\title{
Management of Charcot-Marie-Tooth disease: improving long-term care with a multidisciplinary approach
}

\author{
This article was published in the following Dove Press journal: \\ Journal of Multidisciplinary Healthcare \\ 19 January 2016 \\ Number of times this article has been viewed
}

\section{Donald McCorquodale \\ Evan M Pucillo \\ Nicholas E Johnson \\ Department of Neurology, Eccles Institute of Human Genetics, University of Utah, Salt Lake City, UT, USA}

Correspondence: Nicholas E Johnson Department of Neurology, Eccles Institute of Human Genetics, University of Utah, I5N 2030 E 2270A Salt Lake

City, UT 84II2, USA

Tel +l 80I 5857575

Email nicholas.johnson@hsc.utah.edu

\begin{abstract}
Charcot-Marie-Tooth (CMT) disease is the most common inherited neuropathy and one of the most common inherited diseases in humans. The diagnosis of CMT is traditionally made by the neurologic specialist, yet the optimal management of CMT patients includes genetic counselors, physical and occupational therapists, physiatrists, orthotists, mental health providers, and community resources. Rapidly developing genetic discoveries and novel gene discovery techniques continue to add a growing number of genetic subtypes of CMT. The first large clinical natural history and therapeutic trials have added to our knowledge of each CMT subtype and revealed how CMT impacts patient quality of life. In this review, we discuss several important trends in CMT research factors that will require a collaborative multidisciplinary approach. These include the development of large multicenter patient registries, standardized clinical instruments to assess disease progression and disability, and increasing recognition and use of patient-reported outcome measures. These developments will continue to guide strategies in long-term multidisciplinary efforts to maintain quality of life and preserve functionality in CMT patients.
\end{abstract}

Keywords: rehabilitation, genetic diagnosis, patient quality of life, inherited neuropathies, hereditary motor and sensory neuropathies, longitudinal care

\section{Introduction}

Charcot-Marie-Tooth (CMT) disease is the most common inherited neuropathy, and with an estimated prevalence of one in 2,500, one of the most common inherited diseases in humans. CMT is a disorder that most commonly causes progressive distal to proximal weakness and associated atrophy as well as sensory deficits, usually affecting the feet and legs at onset. It progresses in a length-dependent fashion eventually affecting the hands, but its clinical phenotype can range from mild functional limitations to severe complicated diseases. It is broadly classified as demyelinating or an axonal form, though intermediate forms exist, each with specific histopathologic, electrodiagnostic, and genetic features. While neurologic examination, electrodiagnostic techniques, and genetic testing yield diagnostic and prognostic information, a multidisciplinary supportive care team is critical to improve the quality of life (QoL) in patients for this still incurable disease.

\section{Classification, epidemiology, and genetics}

CMT classically refers to inherited motor and sensory neuropathies with a wide range of genotypes and phenotypes. Classification of the various types of CMT was originally described by Dyck et al in 1975 and employed the term "hereditary motor 
and sensory neuropathy types I-VII", also referred to CMT types $1-7.1,2$ These distinctions rely on electrodiagnostic findings of either nerve conduction slowing, representing demyelinating disease, or decreased compound muscle action potential (CMAP) amplitudes, representing axonal injury, as well as the presence of other clinical features. This classification system described other hereditary sensory and sensory-autonomic neuropathies, but did not include other primary inherited neuropathies such as hereditary neuropathy with pressure palsy and giant axonal neuropathy.

While this classification system has provided a useful basis to better understand clinical, pathological, and electrodiagnostic phenotype variability, identification of genetic etiologies has furthered our understanding of the pathogenesis of CMT and allowed for further clinical refinement. The most commonly encountered forms of CMT are generally classified as type 1 (demyelinating) and type 2 (axonal). Occasional cases share features of both axonal and demyelinating forms with intermediate conduction velocities, and have been recently reviewed by Nicholson and Myers. ${ }^{3}$ For each CMT subtype, the known genetic classification is denoted as a letter to identify the genetic etiology. An overview of single gene causes of CMT based on inheritance patterns, pathology, and genetics had been simplified and described by Bird and is summarized in Table $1 .{ }^{4}$ It should be noted that there are rare allelic and complex CMT disorders; for instance, mutations in MFN2 that cause CMT2A and rare forms such as CMT6. ${ }^{5,6}$

The prevalence of CMT has been estimated as one in 2,500 , but depending on geographic populations studied, this estimate has ranged from one in $\sim 1,200$ to $9,200 .^{7-10}$ With respect to the subtypes of CMT, CMT type 1 is thought most common, representing approximately half to $80 \%$ of all CMT. ${ }^{1-14}$ In certain populations (Japan) or when sporadic cases are included, a higher prevalence of CMT2 is observed. Intermediate forms, which share features of types 1 and 2, consistently make up $<4 \%$ of cases. In CMT type 1, PMP22 duplication (CMT1A) make up the vast majority, with North American studies in clinical populations consistently showing that $P M P 22$ duplication and point mutations account for $\sim 50 \%$ or more of CMT1; international studies are variable and report ranges from $13 \%$ to $67 \%$. The remaining genes known to cause CMT1 (LITAF, EGR2, and NEFL) likely account for $\sim 10 \%$ or less of CMT1. In CMT type 2, mutations in MFN2 (CMT2A) are thought to account for $15 \%-20 \%$ of CMT2 in clinical studies, with other CMT2 genes (Rab7, TRPV4, GARS,
NEFL, $H S P B 1, G D A P, H S P B 8)$ accounting for a very small minority of cases. ${ }^{6,15-17}$

\section{Clinical diagnosis}

The classic CMT patient will usually present with complaints of lower extremity weakness, foot drop, and foot deformity which is familial. Examination reveals sensory deficits and motor weakness distally with associated muscular atrophy and absent deep tendon reflexes. If there is a family history of similar symptoms or diagnosis of neuropathy, CMT is a likely diagnosis if no other neurologic signs or symptoms are revealed. In cases without a clear family history, other neurologic diagnosis within the family should be explored, as family members may have been incorrectly diagnosed. In both sporadic and hereditary cases, reversible causes of neuropathy should be ruled out, and nerve conduction studies should be performed to confirm the diagnosis, distinguish from other neurologic entities, and further classify the CMT type. In rare cases, CMT may present with other neurologic symptoms, such as optic atrophy, ataxia, and spasticity. Careful evaluation and consideration is recommended for rare CMT subtypes or alternative neurologic diagnoses. More detailed discussion of clinical diagnosis can be found in several recent publications focusing on this topic. ${ }^{18,19}$

\section{Genetic diagnosis and counseling}

With electrodiagnostic confirmation and classification of CMT, the decision to pursue genetic testing depends on many factors. A genetic counselor is an invaluable member of the multidisciplinary team and can be essential in helping the patient navigate the ethical, financial, and technical aspects of genetic testing. Certainly for women in their reproductive years, the confirmation of a heritable disease can have an impact on reproductive decisions. Likewise, an asymptomatic but concerned member of a known affected family may have an interest in genetic testing. However, beyond genetic confirmation of the diagnosis, the results of genetic testing do not currently influence subsequent treatment or management of CMT. Even with the decreasing cost of commercial testing, it still remains expensive and the patient may encounter problems with insurance coverage for testing. Beyond testing the most common genes, there are diminishing returns in testing the increasing number of rare genes unless a specific sign, symptom, or inheritance pattern allows for a more specific approach. In a large study of $\sim 18,000$ individuals referred to commercial testing for CMT, mutations were identified in $\sim 18 \%$, leaving the large majority without a clear genetic etiology. ${ }^{12}$ Of the patients with identified mutations, $94.9 \%$ 
Table I Overview of CMT clinical type and genetic subtypes

\begin{tabular}{|c|c|c|c|c|c|}
\hline Type & Pathology/phenotype & Inheritance & $\%$ of CMT & Subtype and gene & \\
\hline \multirow[t]{6}{*}{ CMTI } & - Myelin abnormalities & $A D$ & $50-80$ & CMTIA & PMP22 \\
\hline & - Distal weakness, atrophy, & & & CMTIB & MPZ \\
\hline & and sensory loss & & & CMTIC & LITAF \\
\hline & - Onset: $\sim 5-\sim 20$ years & & & CMTID & EGR2 \\
\hline & - Motor NCV $<38 \mathrm{~m} / \mathrm{s}$ & & & CMTIE & PMP22 \\
\hline & & & & CMTIF/2E & NEFL \\
\hline \multirow[t]{17}{*}{ CMT2 } & - Axonal degeneration & $A D$ & $10-15$ & CMT2A & MFN2 \\
\hline & - Distal weakness and atrophy, & & & СМТ2B & $R A B 7 A$ \\
\hline & variable sensory involvement & & & СМт2C & TRPV4 \\
\hline & - Complicated and severe & & & CMT2D & GARS \\
\hline & cases described & & & CMT2E/IF & NEFL \\
\hline & - Motor NCV >38 m/s & & & $\mathrm{CMT} 2 \mathrm{~F}$ & HSPBI \\
\hline & - Onset: variable & & & CMT2G & $12 q 12-q 13$ \\
\hline & & & & $\mathrm{CMT} 2 \mathrm{H} / 2 \mathrm{~K}$ & GDAPI \\
\hline & & & & CMT2I/2J & $M P Z$ \\
\hline & & & & CMT2L & HSPB8 \\
\hline & & & & $\mathrm{CMT} 2 \mathrm{~N}$ & AARS \\
\hline & & & & СМT2M & $D M N$ \\
\hline & & & & СMT2O & DYNCIHI \\
\hline & & & & CMT2P & LRSAM I \\
\hline & & & & CMT2S & $I G H M B P 2$ \\
\hline & & & & СMT2T & DNAJB2 \\
\hline & & & & СMT2U & MARS \\
\hline Intermediate & - Myelinopathy and axonal & $A D$ & $<4$ & DI-CMTA & Unknown \\
\hline \multirow[t]{4}{*}{ form } & - Motor NCV $>25 \mathrm{~m} / \mathrm{s}$ and & & & DI-CMTB & DNM2 \\
\hline & $<38 \mathrm{~m} / \mathrm{s}$ & & & DI-CMTC & YARS \\
\hline & & & & DI-CMTD & $M P Z$ \\
\hline & & & & DI-CMTF & GNB4 \\
\hline \multirow[t]{13}{*}{ CMT4 } & - Demyelinating & $A R$ & Rare & CMT4A & GDAPI \\
\hline & - Recessive & & & CMT4BI & MTMR2 \\
\hline & - Variable presentations/ & & & CMT4B2 & SBF2 \\
\hline & phenotypes & & & CMT4B3 & SBFI \\
\hline & & & & CMT4C & SH3TC2 \\
\hline & & & & CMT4D & NDRGI \\
\hline & & & & CMT4E & EGR2 \\
\hline & & & & CMT4F & $P R X$ \\
\hline & & & & CMT4G & $H K I$ \\
\hline & & & & $\mathrm{CMT} 4 \mathrm{H}$ & FGD4 \\
\hline & & & & CMT4J & FIG4 \\
\hline & & & & СMT2BI & LMNA \\
\hline & & & & СМТ2B2 & MED25 \\
\hline \multirow[t]{6}{*}{ CMTX } & - Axonal degeneration with & $X L$ & $10-15$ & CMTXI & $G J B I$ \\
\hline & myelin abnormalities & & & CMTX2 & $X p 22.2$ \\
\hline & & & & СMTX3 & Unknown \\
\hline & & & & CMTX4 & AIFMI \\
\hline & & & & СMTX5 & PRPSI \\
\hline & & & & СМТХ6 & PDK3 \\
\hline
\end{tabular}

Abbreviations: CMT, Charcot-Marie-Tooth; NCV, nerve conduction velocity; AR, autosomal recessive; AD, autosomal dominant; XL, X-linked.

had mutations in $P M P 22, M P Z, M F N 2$, or GJB1. These numbers are not in agreement with previous studies which report $\sim 60 \%$ diagnostic rate with genetic testing in confirmed CMT populations, likely reflecting differences in selection of patients for genetic testing between $\mathrm{CMT} /$ neuromuscular specialists and non specialists. ${ }^{20}$
The advent of next-generation sequencing which can look for mutations in CMT gene panels, whole exome or genome, can circumvent complex and potentially costly algorithmic approaches with parallel sequencing panels of CMT genes, the whole exome, or even whole genome. ${ }^{12,21}$ However, the problem of identifying disease-causing variants not previously 
described in the literature over variants of unknown significance is a significant barrier not unique to CMT. Sequence databases, such as the NHLBI Exome Sequencing Project Exome Variant Server (http://evs.gs.washington.edu/EVS/), can be a helpful aid in discerning common polymorphisms from rare putative disease-causing variants. An invaluable resource for referencing disease-causing variants is the Mutation Database of Inherited Peripheral Neuropathies (IPNMDB) curated by Vincet Timmerman at the University of Antwerp (http://www.molgen.ua.ac.be/CMTMutations/ Home/Default.cfm). Beyond its evolving commercial application in identifying known disease-causing mutations, whole exome and whole genome sequencing remains an important research tool in the search for new CMT genes, adding to a list of over 870 mutations across more than 80 genes. However, a cost conscious sequential approach should be taken by the clinician, as four genes (PMP22 duplication, GJB1, MPZ, $M F N 2$ ) represent $>90 \%$ of familial CMT cases. A focused CMT gene panel would reasonably precede whole exome or genome sequencing in order to optimize costs, time, and chances of diagnostic genetic achievement.

With such a complicated clinical and genetic heterogeneity, genetic counseling is an essential component of multidisciplinary care for the CMT patient. Many times, the genetic counselor directly deals with the emotional and psychosocial consequences of the loss of independence, emotional pain, embarrassment, stress around reproduction, the impact of wearing orthopedic devices, and anxiety over imminent progressive disability. ${ }^{22}$ A recent review of genetic counseling in CMT described the benefits of genetic testing as: 1) establishing the diagnosis and subtype; 2) confirming inheritance pattern which may be important in reproductive counseling; 3 ) allow for option of prenatal or pre implantation diagnosis and targeted testing of other family members; 4) allows for participation in natural history studies and clinical trials which are genotype or CMT subtype focused; 5) allows for more refined prognostication based on the published literature about the specific mutation; and 6) allows for diagnosed patients to connect with members of the CMT community with the same diagnosis. ${ }^{23}$ The same review suggested that a standard genetic counseling meeting with CMT patients should optimally address the aforementioned items as well as providing support group information or other community resources, assessment of need for work and home support service, determination of workplace and insurance compliance with Americans with Disabilities Act and Genetic Information Nondiscrimination Act of 2008, assessment of the psychosocial impact of diagnosis, discussion of possible delays and misdiagnosis prior to confirmed CMT diagnosis, short discussion of symptomatic treatments and encouragement to participate in CMT research studies.

\section{Natural history}

CMT is a progressive disease with a wide range of age of onset and severity. The classically described clinical presentation developed prior to knowledge of its genetic heterogeneity and given our current understanding of genetic prevalence, likely best describes CMT1. Indeed, the only CMT types with natural history data are CMT1A and CMTX. The natural history of CMT2 or more rare CMT subtypes has yet to be described. What follows is a description of CMT treated as a generalized disease entity.

Both demyelinating and axonal forms of CMT are thought of as a length-dependent disease process, which first affects the distal lower extremities. Its progression is usually steady and slow, except when a known triggering or exacerbating factors such as chemotherapy, trauma, or other stressor such as surgery can precipitate symptoms in the asymptomatic patient or cause a temporary acceleration of progression.

Symmetric strength deficits are hallmark features and are typically seen mostly distal to the knee, but also in the wrist and hand as the disease progresses into later stages. Mild-to-moderate proximal musculature weakness and tremors may also develop in later stages of CMT. Pes cavus, equinovarus, hammertoes, and claw-hand deformities are often prevalent in many patients with $\mathrm{CMT}^{24}$ On examination, loss of light touch, proprioception, vibration, hot/ cold, and pain may be present at diagnosis and with disease progression. Most patients with CMT do not initially complain of any loss of sensation; however, it is often present on physical examination. There can be varying degrees of sensory involvement, but by the time sensory symptoms reach the knee, they often begin in the hands in a classic stocking-glove distribution.

Weakness in the anterior lower leg muscles of dorsiflexion may frequently lead to "foot drop" and can have a strong impact on ambulation and function, and more affected patients could eventually progress to a non-ambulatory status confined to a wheelchair. ${ }^{25-27}$ Subsequent weakness in the peroneal muscles of eversion in the lower leg could also allow for excessive inversion and instability at the ankle joint, making the patient particularly vulnerable to sprains and falls. ${ }^{28}$ Also notable, weakness in ankle dorsiflexors may lead to subsequent tightening of the gastrocnemius, soleus, and fibrotic changes in the heel cord Achilles tendon, and may 
put the patient at risk for developing an ankle contracture. ${ }^{25,28}$ Very late-stage or severe impairments may cause contraction of the unopposed antagonist muscles of the legs, and even in the hands. ${ }^{25,27}$

\section{Electrodiagnostic features}

As mentioned earlier, classification of CMT is based on electrodiagnostic findings of either nerve conduction slowing $(<38 \mathrm{~m} / \mathrm{s})$ in demyelinating forms, or decreased CMAP amplitudes with preserved conduction speeds in axonal forms. Occasionally, nerve conduction slowing may fall into intermediate range between $25 \mathrm{~m} / \mathrm{s}$ and $45 \mathrm{~m} / \mathrm{s}$ and is coined intermediate CMT. Studies of demyelinating CMT (CMT1A) have shown that while demyelination and slowing of nerve conduction velocities appear to be the initial pathological insult, secondary axonal loss as measured by CMAP amplitudes and motor unit number estimation (MUNE) correlated better with patients' progressive weakness than changes in nerve conduction velocity (NCV) ${ }^{29-32}$ In children with CMT, electrophysiological changes can be detected as early as 2 years of age, with abnormally small CMAPs and progressively worsening NCV until approximately 6 years of age when it stabilizes. ${ }^{33}$ Similar loss of axons has been observed in CMT2, with more proximal involvement and without changes in $\mathrm{NCV}^{29}$ In a study, it appears that at least in CMT1A, the largest amount of axonal loss occurs early in the disease, with rates of axonal loss when approaching age-matched controls, but with a lower underlying reserve. ${ }^{30}$ A 5-year longitudinal study of the natural history of CMT1A revealed that over 5 years, electrodiagnostic evidence of the rate of axonal injury and changes in measured grip strength by dynamometry were not different from age-matched controls, but perceived levels of disability were significantly worse. ${ }^{34}$ It has been suggested that progressive disability stems from worsening muscle weakness and secondary skeletal deformities. ${ }^{30,34}$ The results of two Italian natural history studies in CMT1A and CMT2 describe decreases in distal muscle strength and worsening sensation, but no difference in QoL, depression, or disability over a 2-year period. ${ }^{35,36}$

\section{QoL}

While CMT patients consistently score lower than healthy subjects in QoL measures, there is not a direct longitudinal relation between QoL and physical function or disability. ${ }^{37}$ The observed paradox between progressive disability and preserved QoL measured with instruments such as the Short Form-36 has been discussed, and former methods for assessing both disability and QoL may not be optimal for detecting pertinent patient-based outcomes. ${ }^{38}$ There has been an attempt to infer disease impact and QoL from clinical examination findings. Initial studies suggested that tactile sensory tests related to emotional component of QoL, ability to walk on toes and heel related to disability and bodily pain. ${ }^{39}$ Upper extremity weakness was the most sensitive marker of overall disability as lower extremity strength is impaired in all CMT patients and likely reaching a ceiling effect early in the disease. A study has demonstrated lower leg weakness and cramping correlated with low QoL. ${ }^{40}$ This same study found worse physical functioning scores as compared to patients with epilepsy, diabetes mellitus, angina, and stroke patients suggesting that the impact of CMT on QoL had previously been underestimated.

There have been descriptions of the natural history of CMT1 and CMTX, but prior to the last decade, the relative rareness of CMT did not allow individual centers to follow enough patients to sufficiently power rigorous observational studies (particularly of more rare subtypes) or entertain the notion of therapeutic trials. Furthermore, there was a lack of highly developed disease-specific clinical instruments to describe and quantify disease severity. Over the past decade, several important developments have co evolved with the emergence of CMT therapeutic trials that address these shortcomings. The Inherited Neuropathies Consortium (INC; https://www.rarediseasesnetwork.org/INC/), part of the Rare Diseases Clinical Research Network includes $\sim 17$ multinational sites that collect clinical, electrodiagnostic, and genetic data from CMT patients. The INC will play a pivotal role in registering CMT patients in sufficient numbers to begin to power observational studies across multiple clinical sites.

Another key development is an evolving armament of clinical instruments designed to standardize outcome measures required for observational studies and therapeutic trials. The CMT neuropathy score (CMTNS) is a 36-point composite score that rates the patient's symptoms, signs, and neurophysiology, and has been validated as a reproducible measure of disability in both axonal and demyelinating forms of CMT. ${ }^{41-43}$ It was designed to improve standardization of longitudinal, therapeutic, and multicenter studies. There were some initial criticisms that the original CMTNS failed to have translatable value in rehabilitation, and lacked sensitivity related to gross motor and sensory scoring. ${ }^{44}-46$ Many of these opinions and observed floor and ceiling effects that limited the responsiveness of scores to meaningful clinical changes over time were addressed and modified in the CMTNS version $2 .{ }^{45}$ The CMTNS version 2 is used to classify CMT patients into mild ( $<10$, usually walk normally with 
occasional tripping), moderate (11-20, usually walk independently but require ankle-foot orthotic), or severe ( $>20$, usually require walker or wheelchair) disease. It has been used as primary endpoints in therapeutic trials, and in natural history studies as discussed in the "Physical therapy and orthoses" section. ${ }^{13,16,20,34,47-51}$ The CMT examination score can be used in patients without electrodiagnostic data, and is simply the sum of non-neurophysiologic data on the CMTNS. ${ }^{41}$ The CMT pediatric examination score is another physician determined age-adjusted functional assessment score designed to assess disability in children. ${ }^{43,52}$ Many other outcome measures of impairment and disability have been implemented and studied in CMT - some as secondary outcome measures in trials. A thorough cataloging of instruments can be found in the "168th ENMC International Workshop Report". ${ }^{46}$ In response to the observed paradox between progressive disability and preserved QoL outcomes, there is a consensus that there remains a need for development of a more sensitive CMT-specific QoL measure. ${ }^{46}$ The recently developed mobility-Disability Severity Index is a patient-reported instrument designed by experienced CMT practitioners that may offer a complimentary outcome measure based on patient perspectives. ${ }^{53}$ A separate large-scale INC registry based study used a survey instrument based on CMT1A patient input over 20 themes using a six-point Likert scale and demonstrated novel themes as prioritized by patients and yielded valuable information on symptom progression. ${ }^{54}$ While the use of the aforementioned instruments will continue to evolve, those involved in the optimal multidisciplinary care of CMT patients will be required to implement and interpret them effectively. Ideally, the aforementioned instruments and outcome measures will eventually have generalized utility for the neurologist, genetic counselor, physical and occupational therapist, and physiatrist caring for the CMT patient.

A large survey of over 400 CMT patients in the INC Rare Disease Clinical Research Network Contact registry identified patient-reported foot and ankle weakness, balance, mobility and hand/finger weakness as the most prevalent themes that affected QoL, but also demonstrated that fatigue, pain, and body image are likely under-recognized influences on perceived QoL. ${ }^{54}$ Besides function limiting themes such as poor balance and mobility limitations, individual symptoms reported as most impactful include difficulty/inability to run, trouble when getting around slippery surfaces, and trouble walking distances and on rough ground. The impact of symptoms appear to have the largest effect over the first 10 years following diagnosis, with a less rapid increase over the ensuing years, so that disease progression is better predicted by duration than by age. While this may be due to survivor bias and improved coping strategies, it also argues for more aggressive multidisciplinary supportive care over the first decade after diagnosis. The results of such studies demonstrate the power of large-scale registry and patient-based reporting to identify diverse sets of issues important to patients' QoL that fall outside the realm of a single discipline.

\section{Clinical surveillance of comorbidities, complications, and medications to avoid}

Beyond monitoring for and treating physical impairments, there is evidence for less well recognized comorbidities and complications in CMT. As mentioned earlier, these underappreciated problems likely negatively impact QoL, but in many cases may be treatable.

Prospective studies regarding the location, severity duration, triggering factors, and impact on QoL of cramps in CMT demonstrated that hand, finger, thigh, and trunk muscle cramps are a stable symptom that clearly impacted QoL. ${ }^{40,54}$ In pediatric CMT1A, muscle cramps, tremor, and distal weakness were shown to be associated with lower QoL measures.52 Adoption of formerly off-label drugs for CMT-related symptoms, such a mexiletine for cramping, will likely lead to new indications and improved QoL for CMT patients.

Respiratory and sleep disorders observed in CMT include restrictive pulmonary impairment, obstructive sleep apnea, restless legs syndrome, and vocal cord dysfunction/laryngeal neuropathy. ${ }^{55}$ In a large German web-based survey study of over 200 CMT patients, CMT patients reported more fatigue, daytime sleepiness, and poorer sleep quality as well as a three fold increase in restless leg syndrome. ${ }^{56} \mathrm{~A}$ number of small reports describe symptoms of dyspnea, dysphagia, and obstructive sleep apnea, laryngoscopic evaluation of the upper airway, as well as treatment with continuous or bi-level positive airway pressure. ${ }^{55,57-62}$ While there is not enough evidence to make recommendations regarding clinical screening for sleep and respiratory disorders, longitudinal care should optimally address these potential comorbidities.

Worsening of CMT symptoms during pregnancy has been reported. ${ }^{63}$ This observation has led to investigations into progesterone antagonism as a possible therapy in CMT, which is discussed in more detail in the "Therapeutics" section. CMT was shown to increase the risk for complications during delivery, specifically abnormal birth presentation 
and post partum bleed, and with higher rates of emergency interventions during delivery. ${ }^{64}$ While there are no evidencebased recommendations regarding obstetric anesthesia, it is thought that regional anesthesia is an appropriate alternative to general anesthesia in CMT patients. ${ }^{65} \mathrm{CMT}$ should be considered an independent risk factor for complication during pregnancy and delivery and warrants involvement of a multidisciplinary team.

Many medications are known to have the potential to worsen CMT. The prototypical neurotoxic offenders are chemotherapies such as taxols and the vinca alkaloids that target microtubules. ${ }^{66}$ These microtubule depolymerizing agents are thought to interrupt axonal transport along microtubules and worsen preexisting neuropathy or even precipitate new neuropathy. This observation has been used to bolster the idea that axonal transport explains the length-dependent progression of CMT. ${ }^{67}$ Chemotherapies are not the only offending agents, and a list of potentially exacerbating medications organized by certainty of risk is maintained and updated by the CMT Association (http://www.cmtausa.org/). ${ }^{68}$

\section{Therapeutics}

While the last decade has seen the first CMT clinical trials, there are no clinical data supporting use of medications, and the management of CMT remains supportive. The mainstay of supportive care is physical therapy as discussed in the next sections. While many drugs are under examination, there is only one ongoing clinical trial (PLEO-CMT, ClinicalTrials. gov identifier NCT02579759) in humans of combination of baclofen, naltrexone, and sorbitol (PXT3003). ${ }^{69-71}$

Clinical trials have been largely driven by observation in animal models of CMT1A. The bulk of clinical trial efforts centered around the use of ascorbic acid, a known promoter of myelination which has been shown to reduce expression levels of PMP22, improve locomotor function, and prolong life in CMT1A rodent models. ${ }^{72}$ This led to a randomized double-blind, placebo controlled trial of high dose ascorbic acid (30 mg/kg/day) in children, with a primary endpoint of median nerve motor conduction at 1 year, and secondary outcomes of foot and hand strength, motor function, walking ability, and QoL. ${ }^{73} \mathrm{~A}$ total of 80 children completed the trial, and a non significant increase in median nerve conduction motor velocity was observed, with no difference in secondary outcomes. A similar study in adult CMT1A patients $(\mathrm{N}=179)$ randomized to $1 \mathrm{~g}$ or $3 \mathrm{~g}$ of ascorbic acid a day or placebo used the CMTNS at 1 year as the primary outcome and included secondary outcome measures of muscle strength, gait velocity, disability, fatigue, pain, and cramping scales, as well as the global impression severity score. ${ }^{74}$ No significant differences in primary or secondary outcomes were observed. A third randomized, high dose ascorbic acid (1 g twice daily), double-blind study in young adults (age $<25$ years, $\mathrm{N}=11$ ) using a primary outcome of median NCV and neurophysiological secondary outcome measures, failed to show any significant effect. ${ }^{75}$ In these studies, the high doses of ascorbic acid treatment were well tolerated. Given the non significant results and the slow progression of the disease, it was thought that a 1-year follow-up may not have been long enough to capture the effect of ascorbic acid. Two subsequent 2-year trials of low and high doses of ascorbic acid (1.5 g/ day, $\mathrm{N}=277$ and $4 \mathrm{~g} /$ day, $\mathrm{N}=110$ ) in adults failed to show significant differences in similar outcome measures. ${ }^{76,77}$

A number of smaller non randomized non-blinded studies have shown potential promise in agents such as coenzyme Q10, linoleic acid, and potassium channel blockers, but rigorous clinical data are lacking. ${ }^{78,79}$ The observation that in a small cohort of female CMT1 patients ( $\mathrm{N}=21,45$ gestations), 38\% experienced a worsening of CMT symptoms during pregnancy suggests a possible link with pregnancy-associated hormonal changes. ${ }^{63}$ Transgenic rat models of CMT1A implicated progesterone receptors on Schwann cells as mediating this link to progesterone during pregnancy. Administering exogenous progesterone to CMT1A drove the CMT phenotype, and progesterone antagonists reduced $P M P 22$ expression and improved CMT phenotypes. ${ }^{80}$ Further studies demonstrated that antiprogesterone therapy improved motor strength and axonal loss, but did not change myelin thickness or nerve conduction velocities, effectively uncoupling axonal loss from demyelination. ${ }^{81}$ Formal clinical trials of anti-progesterone therapy in CMT have yet to be reported, largely due to the significant side effect profile of current anti-progesterones. Additional investigations into coenzyme Q10, curcumin, NTF3, and other study drugs are at various stages of development. ${ }^{46,82,83}$

\section{Physical therapy and orthoses}

While there are distinct genetic causes, neurophysiological properties, and underlying disease mechanisms, the physical deficits of CMT are uniform enough to approximate and discuss it as a singular entity. Future studies of CMT subtypes may reveal important differences in response to physical therapies, orthotics, and more specific recommendations regarding exercise. Likewise, data collection from large national patient registries may help investigators retrospectively analyze which durable medical equipment and adaptive devices are best suited for improving function in patients with CMT along the natural history of the disease. 
Important aspects of physical therapy and rehabilitation for patients with CMT may involve gait training, therapeutic exercise, stretching, balance and postural stabilization, fall risk prevention strategies, aquatic therapy, energy conservation techniques, serial casting/night splinting, patient education, training on appropriate assistive devices, and prevention of secondary impairments. ${ }^{25-28,84-91}$ Likewise, time should be taken to educate the patient on lifestyle modifications and energy conservation techniques along with the progression of the disease and impairments in body structures and function. ${ }^{89}$

Protection of joint range of motion (ROM) to avoid the possibility of contractures and maximize functional use of all extremities should be stressed in the management of CMT. ${ }^{25}$ Night splinting, however, according to the most current evidence does not appear to be the most effective means for long-term improvements in ankle ROM. ${ }^{28,89}$ Occupational therapy and/or certified hand therapists should be incorporated with managing both early- and late-stage impairments in patients with limited wrist and hand strength and ROM, as well as children with hand dysfunction. ${ }^{92}$ Weakness, pain, dysmetria, difficulty with handwriting, and discoordination, among several other impairments, may greatly affect upper limb function in the patient with CMT as a child or adult and they may benefit greatly from occupational, vocational, and hand therapies to improve compensatory strategies, utilize assistive technology, improve age-appropriate function, and accommodate for their impairment. ${ }^{92}$

Patients with CMT frequently stumble, trip, or fall due to weakness and sensory deficits distal to the knee joint, and often display compensatory strategies in proximal hip and pelvic muscles which are recruited to modify gait patterns. ${ }^{24,90}$ It has been shown that various types of properly fitted ankle-foot orthoses (AFO) may significantly reduce the need for proximal compensations and can improve lower extremity control during ambulation. Similarly, Dufek et al demonstrated that patients with CMT display increased gait speed when using AFO compared to no bracing. ${ }^{93}$ Anterior elastic AFO appear to reduce the energy cost of ambulation in CMT. ${ }^{94}$ After fitting of AFO, patients should receive proper gait training to assist with adapting and normalizing their biomechanics during locomotion, maximizing their functional ambulation potential, and avoiding further compensatory movements for energy efficiency ${ }^{84,93}$ Likewise, patients should be educated on prevention of skin breakdown while wearing orthoses and braces.

Orthoses aimed at offering structural support to focal, and/or global ankle and foot weakness may range from simple shoe inserts to complete AFO bracing, may be plastic or elastic in nature, and may be fabricated from durable plastics to custom carbon-fiber composites..$^{24,28,84-91,93,95-97} \mathrm{~A}$ recent study by Wegener et al demonstrated that in a small population of adult patients with CMT sensorimotor in-shoe orthoses proved to be more comfortable, better cushioned, and had a positive effect on overall lower extremity kinematics during ambulation..$^{98}$ A comprehensive evaluation of ROM, sensation, reflexes, strength, and balance should be performed when deciding which AFO device is best suited for each individual patient. Despite their effectiveness in improving gait, foot pain, and mild balance impairments in patients with CMT, adherence to AFO-wearing schedules remains poor. ${ }^{96}$ Poor compliance with wearing AFO in CMT has been well documented across various age ranges in recent studies, often for comfort and cosmetic reasons..$^{99,100}$

Surgical correction may be required in cases of chronic ankle sprains, shoe-wearing difficulty, and pain not helped by orthoses. ${ }^{24}$ Surgical goals are to realign joints, correct boney deformities, and to balance muscles, and require a high degree of individualization. Evaluation of foot alignment, strength, and weight-bearing radiographs are used to guide the surgeon's strategy.

Surgery for foot deformities is common in CMT patients yet a systematic review is lacking. Some recent reports have suggested early minimally invasive procedures including plantar fasciotomy, Achilles tendon lengthening, transfer of the peroneus longus to the fifth metatarsal, tendon transfer, and hammertoe correction may preserve the utility of braces and reduce the need for further surgery. ${ }^{101,102}$ The aim of an early minimally invasive approach is to decrease the forces and intrinsic/extrinsic muscle imbalances that underlie progressive foot deformity. Later stage reconstructive surgery usually includes staged procedures of tendon lengthening and or transfer, osteotomy, and arthrodesis. ${ }^{101,102}$ In the more severe forms of CMT, orthopedic correction of spinal deformity and hip dysplasia may be required. For a more detailed review of surgical and orthopedic issues in CMT, the reader is referred to Yagerman et al. ${ }^{24}$

Overwork weakness is another common finding throughout neuromuscular disorders that may require adaptation and utilization of energy conservation techniques. ${ }^{89,90}$ Although there is conflicting evidence on the concept of overwork weakness, recent findings of bilateral hand and leg strength suggests it may not manifest in CMT as previously thought, and this phenomenon may be more individualized to each patient case..$^{90}$ Therefore, low-to-moderate-intensity exercise should be regularly encouraged as it should have overall systemic health benefits..$^{25,26,90,103}$ Interval training, 
by its very nature incorporating periods of rest and exercise, appears to display marked improvements in cardiorespiratory, strength, and functional capacities, and likely slows or reverses the deconditioning process often seen in patients with $\mathrm{CMT}^{26,104,105}$

Low-intensity exercise appears to be more beneficial for patients with neuromuscular disease when compared to high-resistance or high-intensity exercise. ${ }^{25}$ Aquatic therapy, in theory, may be of great benefit due to its unweighting properties and dynamic resistance during underwater movements, but more evidence and studies are needed in this area. Likewise, a home-based resistance training exercise program focused on activities of daily living (ADL)-specific exercises improved strength and ADL equally in both adult males and females with CMT. ${ }^{105}$ Stretching should play an important role in the maintenance of patients with CMT to protect joint ROM in order to optimize the functional use of their extremities as their weakness persists. Occupational therapy should also be considered for those patients needing adaptive equipment and further training to improve independence with self-care and ADL.

Patients with CMT will commonly present with increasing sensorimotor loss distal to the knee that will greatly benefit from AFO and the ongoing care of an orthotist. Also, interval training, and low- to-moderate-intensity aerobic and resistance exercise can be therapeutic and is not likely to negatively impact a patient's function. Energy conservation techniques and lifestyle modifications are key educational concepts for the patient with CMT, albeit, are very patientspecific. Often patients with CMT will develop weakness and limited ROM in their wrists and hands in later stages that can be addressed by skilled hand therapists, and occupational and physical therapy modalities. Patients with CMT should invariably be part of an ongoing multidisciplinary plan of care in regards to their functional impairments; including but not limited to: physical and occupational therapist, physiatrist, orthotist, neurologist, and hand therapist, in order to manage each impairment to its fullest and achieve maximum functional benefit. More high-quality trials and evidence are needed to draw sound conclusions on the benefits of aquatic therapy, specific therapeutic modalities, exercising, stretching protocols, balance training, night splinting/serial casting, and assistive technology devices in the management of CMT disease. Likewise, the emergence of large-scale patient registries, such as the INC and well-defined natural histories, will enable researchers to investigate how therapies might be optimally tailored to the needs of specific CMT clinical and genetic subtypes.

\section{The need for multidisciplinary care in CMT}

In summary, while the medical diagnosis of CMT is traditionally made by the neurological specialist, the optimal management of CMT patients includes genetic counselors, physical and occupational therapists, physiatrists, orthotists, social workers, mental health providers, and community resources (Table 2). Continued genetic discoveries continue to add to the complexity of CMT, and knowledge of each CMT subtype will likely shape the way each member of the multidisciplinary team approaches the disease. Several important trends in CMT research discussed earlier, including the development of large multicenter patient registries, standardized clinical instruments to assess disease progression and disability, and increasing recognition of patient-reported factors will likely make significant improvements to CMT patients' QoL. These developments have and will continue to identify novel targetable and treatable

Table 2 Multidisciplinary members and roles in the diagnosis and management of CMT

\begin{tabular}{|c|c|}
\hline Neurologist & $\begin{array}{l}\text { - Evaluation and diagnosis } \\
\text { - Prognostication } \\
\text { - Consideration for research studies } \\
\text { - Referrals to genetic counselors, PT/OT, } \\
\text { mental health } \\
\text { - Longitudinal care and reevaluation } \\
\text { - Counseling on medications to avoid } \\
\text { - Surveillance of comorbidities } \\
\text { - Lifestyle modifications to limit disability }\end{array}$ \\
\hline $\begin{array}{l}\text { Genetic counselor and } \\
\text { social worker }\end{array}$ & $\begin{array}{l}\text { - Guidance in clinical- and research-based } \\
\text { genetic testing } \\
\text { - Ensuring ADA and GINA compliance } \\
\text { - Discussion of family testing } \\
\text { - Reproductive counseling } \\
\text { - Referral to CMT Association and other } \\
\text { community organization }\end{array}$ \\
\hline $\begin{array}{l}\text { Physical and occupational } \\
\text { therapist/physiatrist }\end{array}$ & $\begin{array}{l}\text { - Evaluation of upper and lower } \\
\text { extremity disability } \\
\text { - Prescription for ankle-foot orthotics } \\
\text { - Recommendations for therapeutic } \\
\text { exercise, stretching, balance and } \\
\text { postural stabilization, fall risk } \\
\text { prevention strategies } \\
\text { - Recommendation on exercise, lifestyle } \\
\text { modification to limit disability }\end{array}$ \\
\hline Psychologist/psychiatrist & $\begin{array}{l}\text { Evaluation and treatment of anxiety, } \\
\text { depression, and other psychosocial } \\
\text { impact of diagnosis, such as body image }\end{array}$ \\
\hline Orthopedic surgeon & $\begin{array}{l}\text { - Evaluation and treatment of severe } \\
\text { foot, ankle, hip, and spine deformities }\end{array}$ \\
\hline
\end{tabular}

Abbreviations: CMT, Charcot-Marie-Tooth; ADA, Americans with Disabilities Act; GINA, Genetic Information Nondiscrimination Act of 2008; PT, physical therapist; OT, occupational therapist. 


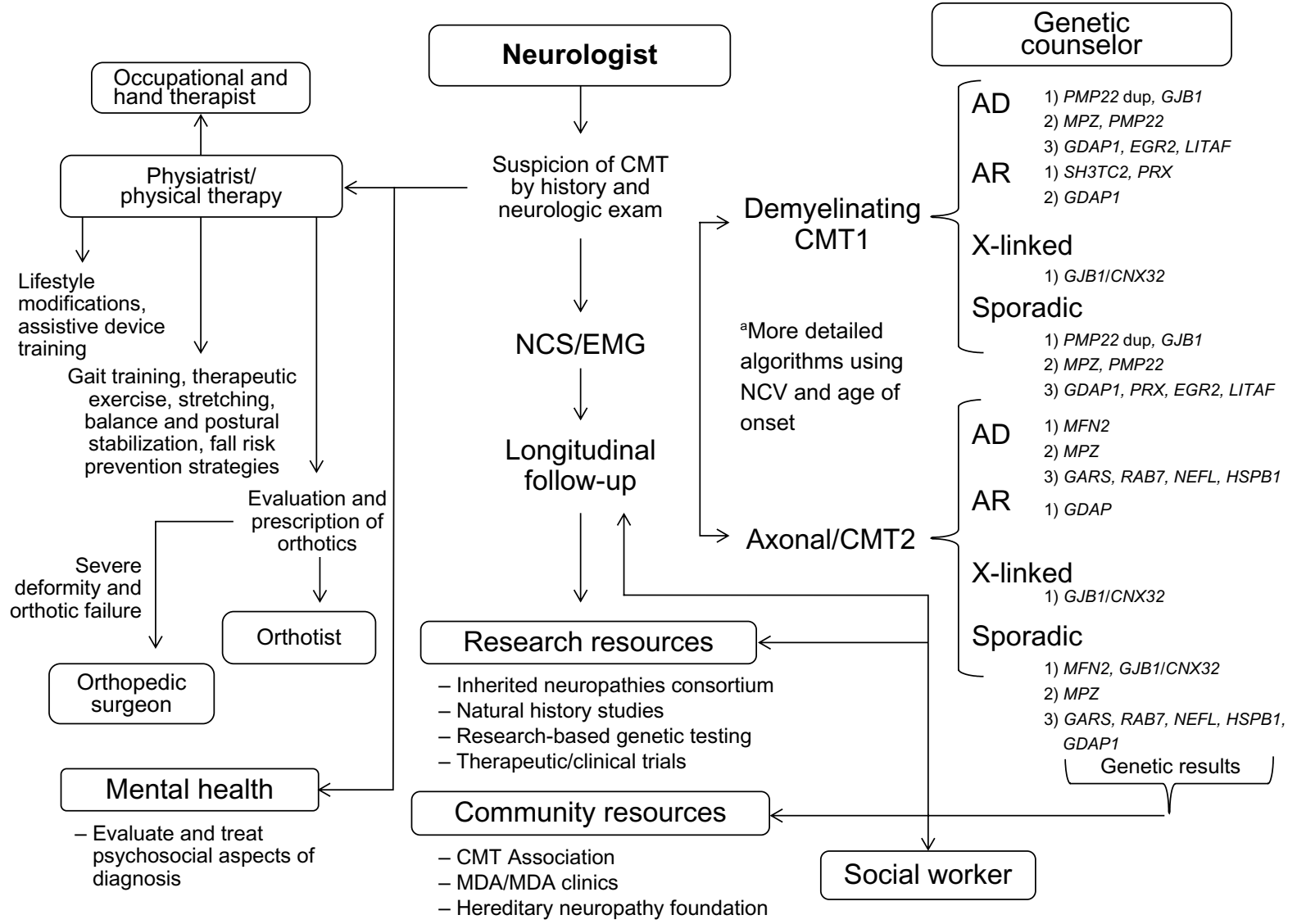

Figure I Flow of multidisciplinary care in diagnosis and management of CMT.

Notes: ${ }^{a} \mathrm{~A}$ simplification of published strategies of genetic testing in CMT as described by Saporta et al ${ }^{106}$ and Miller et al. ${ }^{107}$ The order of genetic testing (I, 2, 3) is guided by electrodiagnostic findings and inheritance pattern. Please refer to Saporta et a ${ }^{106}$ and Miller et al ${ }^{107}$ for more detailed recommendations on strategies of cost conscious sequential genetic testing.

Abbreviations: CMT, Charcot-Marie-Tooth; dup, duplication; NCS, nerve conduction studies; EMG, electromyography; MDA, Muscular Dystrophy Association; AD, autosomal dominant; $A R$, autosomal recessive.

deficits, symptoms, and disabilities that will likely require a collaborative multidisciplinary approach (Figure 1). Many of these multidisciplinary services are coordinated and offered by muscular dystrophy clinics or established CMT-based clinics (Charcot-Marie-Tooth Disease Clinic at the University of Iowa (https://www.uihealthcare.org/charcot-marietooth-disease/). Ongoing CMT research struggles to identify novel therapeutics to slow or stop disease progression, but the evolving strategies in long-term multidisciplinary care of CMT patients is critical in maintaining QoL and functionality with disease progression.

\section{Disclosure}

The authors report no conflicts of interest in this work.

\section{References}

1. Dyck PJ. Inherited neuronal degeneration and atrophy affecting peripheral motor, sensory and autonomic neurons. In: Dyck PJ, Thomas PK, Lambert EH, editors. Peripheral Neuropathy. Philadelphia: WB Saunders; 1975:825-867.
2. Dyck PJ, Lambert EH. Lower motor and primary sensory neuron diseases with peroneal muscular atrophy. II. Neurologic, genetic, and electrophysiologic findings in various neuronal degenerations. Arch Neurol. 1968;18(6):603-618.

3. Nicholson G, Myers S. Intermediate forms of Charcot-Marie-Tooth neuropathy: a review. Neuromolecular Med. 2006;8(1-2):123-130.

4. Bird TD. Charcot-Marie-Tooth Hereditary Neuropathy Overview. In: Pagon RA, Adam MP, Ardinger HH, et al, editors. GeneReviews. Seattle (WA): University of Washington, Seattle; 1993-2015.

5. Zuchner S, De Jonghe P, Jordanova A, et al. Axonal neuropathy with optic atrophy is caused by mutations in mitofusin 2. Ann Neurol. 2006;59(2): 276-281.

6. Verhoeven K, Claeys KG, Zuchner S, et al. MFN2 mutation distribution and genotype/phenotype correlation in Charcot-Marie-Tooth type 2. Brain. 2006;129(Pt 8):2093-2102.

7. Combarros O, Calleja J, Polo JM, Berciano J. Prevalence of hereditary motor and sensory neuropathy in Cantabria. Acta Neurol Scand. 1987; 75(1):9-12.

8. Kurihara S, Adachi Y, Wada K, Awaki E, Harada H, Nakashima K. An epidemiological genetic study of Charcot-Marie-Tooth disease in Western Japan. Neuroepidemiology. 2002;21(5):246-250.

9. Skre H. Genetic and clinical aspects of Charcot-Marie-Tooth's disease. Clin Genet. 1974;6(2):98-118.

10. Wiszniewski W, Szigeti K, Lupski JR. Chapter 126 - Hereditary Motor and Sensory Neuropathies. In: Rimoin DL, Pyeritz RE, Korf B, editors. Emery and Rimoin's Principles and Practice of Medical Genetics. Sixth ed. Oxford, UK: Academic Press; 2013:1-24. 
11. Wise CA, Garcia CA, Davis SN, et al. Molecular analyses of unrelated Charcot-Marie-Tooth (CMT) disease patients suggest a high frequency of the CMTIA duplication. Am J Hum Genet. 1993;53(4): 853-863.

12. DiVincenzo C, Elzinga CD, Medeiros AC, et al. The allelic spectrum of Charcot-Marie-Tooth disease in over 17,000 individuals with neuropathy. Mol Genet Genomic Med. 2014;2(6):522-529.

13. Braathen GJ. Genetic epidemiology of Charcot-Marie-Tooth disease. Acta Neurol Scand Suppl. 2012;(193):iv-22.

14. Braathen GJ, Sand JC, Lobato A, Hoyer H, Russell MB. Genetic epidemiology of Charcot-Marie-Tooth in the general population. Eur J Neurol. 2011;18(1):39-48.

15. Braathen GJ, Sand JC, Lobato A, Høyer H, Russell MB. MFN2 point mutations occur in 3.4\% of Charcot-Marie-Tooth families. An investigation of 232 Norwegian CMT families. BMC Med Genet. 2010; $11: 48$.

16. Casasnovas C, Banchs I, Cassereau J, et al. Phenotypic spectrum of MFN2 mutations in the Spanish population. J Med Genet. 2010;47(4): 249-256

17. McCorquodale DS 3rd, Montenegro G, Peguero A, et al. Mutation screening of mitofusin 2 in Charcot-Marie-Tooth disease type 2. J Neurol. 2011;258(7):1234-1239.

18. Banchs I, Casasnovas C, Alberti A, et al. Diagnosis of Charcot-MarieTooth disease. J Biomed Biotechnol. 2009;2009:985415.

19. Rudnik-Schöneborn S, Tölle D, Senderek J, et al. Diagnostic algorithms in Charcot-Marie-Tooth neuropathies: experiences from a German genetic laboratory on the basis of 1206 index patients. Clin Genet. Epub 2015 Apr 8.

20. Fridman V, Bundy B, Reilly MM, et al. CMT subtypes and disease burden in patients enrolled in the Inherited Neuropathies Consortium natural history study: a cross-sectional analysis. J Neurol Neurosurg Psychiatry. 2015;86(8):873-878.

21. Drew AP, Zhu D, Kidambi A, et al. Improved inherited peripheral neuropathy genetic diagnosis by whole-exome sequencing. Mol Genet genomic Med. 2015;3(2):143-154.

22. Arnold A, McEntagart M, Younger DS. Psychosocial issues that face patients with Charcot-Marie-Tooth disease: The role of genetic counseling. J Genet Couns. 2005;14(4):307-318.

23. Siskind CE, Panchal S, Smith CO, et al. A review of genetic counseling for Charcot Marie Tooth disease (CMT). J Genet Couns. 2013;22(4) 422-436.

24. Yagerman SE, Cross MB, Green DW, Scher DM. Pediatric orthopedic conditions in Charcot-Marie-Tooth disease: a literature review. Curr Opin Pediatr. 2012;24(1):50-56.

25. Abresch RT, Carter GT, Han JJ, McDonald CM. Exercise in neuromuscular diseases. Phys Med Rehabil Clin NAm. 2012;23(3):653-673.

26. Anens E, Emtner M, Hellstrom K. Exploratory study of physical activity in persons with Charcot-Marie-Tooth disease. Arch Phys Med Rehabil. 2015;96(2):260-268.

27. McDonald CM. Clinical approach to the diagnostic evaluation of hereditary and acquired neuromuscular diseases. Phys Med Rehabil Clin NAm. 2012;23(3):495-563.

28. Skalsky AJ, McDonald CM. Prevention and management of limb contractures in neuromuscular diseases. Phys Med Rehabil Clin N Am. 2012;23(3):675-687.

29. Lawson VH, Gordon Smith A, Bromberg MB. Assessment of axonal loss in Charcot-Marie-Tooth neuropathies. Exp Neurol. 2003;184(2):753-757.

30. van Dijk JP, Verhamme C, van Schaik IN, et al. Age-related changes in motor unit number estimates in adult patients with Charcot-Marie-Tooth type 1A. Eur J Neurol. 2010;17(8):1098-1104.

31. Krajewski KM, Lewis RA, Fuerst DR, et al. Neurological dysfunction and axonal degeneration in Charcot-Marie-Tooth disease type 1A. Brain. 2000;123(Pt 7):1516-1527.

32. Krajewski K, Turansky C, Lewis R, et al. Correlation between weakness and axonal loss in patients with CMT1A. Ann N Y Acad Sci. $1999 ; 883: 490-492$.
33. Yiu EM, Burns J, Ryan MM, Ouvrier RA. Neurophysiologic abnormalities in children with Charcot-Marie-Tooth disease type 1A. J Peripher Nerv Syst. 2008;13(3):236-241.

34. Verhamme C, van Schaik IN, Koelman JH, de Haan RJ, de Visser M. The natural history of Charcot-Marie-Tooth type 1A in adults: a 5-year follow-up study. Brain. 2009;132(Pt 12):3252-3262.

35. Padua L, Pareyson D, Aprile I, et al. Natural history of CMT1A including QoL: a 2-year prospective study. Neuromuscul Disord. 2008;18(3):199-203.

36. Padua L, Pareyson D, Aprile I, et al. Natural history of Charcot-MarieTooth 2: 2-year follow-up of muscle strength, walking ability and quality of life. Neurol Sci. 2010;31(2):175-178.

37. Vinci P, Serrao M, Millul A, et al. Quality of life in patients with Charcot-Marie-Tooth disease. Neurology. 2005;65(6):922-924.

38. Shy ME, Rose MR. Charcot-Marie-Tooth disease impairs quality of life: why? And how do we improve it? Neurology. 2005;65(6): 790-791.

39. Padua L, Aprile I, Cavallaro T, et al. Relationship between clinical examination, quality of life, disability and depression in CMT patients: Italian multicenter study. Neurol Sci. 2008;29(3):157-162.

40. Redmond AC, Burns J, Ouvrier RA. Factors that influence health-related quality of life in Australian adults with Charcot-Marie-Tooth disease. Neuromuscul Disord. 2008;18(8):619-625.

41. Shy ME, Blake J, Krajewski K, et al. Reliability and validity of the CMT neuropathy score as a measure of disability. Neurology. 2005;64(7): 1209-1214.

42. Mannil M, Solari A, Leha A, et al. Selected items from the CharcotMarie-Tooth (CMT) Neuropathy Score and secondary clinical outcome measures serve as sensitive clinical markers of disease severity in CMT1A patients. Neuromuscul Disord. 2014;24(11): 1003-1017.

43. Burns J, Ouvrier R, Estilow T, et al. Validation of the Charcot-MarieTooth disease pediatric scale as an outcome measure of disability. Ann Neurol. 2012;71(5):642-652.

44. Vinci P. Perplexity about the use of the Charcot-Marie-Tooth Neuropathy Score in rehabilitation. Eur J Phys Rehabil Med. 2008;44(4): 473-474.

45. Murphy SM, Herrmann DN, McDermott MP, et al. Reliability of the CMT neuropathy score (second version) in Charcot-Marie-Tooth disease. J Peripher Nerv Syst. 2011;16(3):191-198.

46. Reilly MM, Shy ME, Muntoni F, Pareyson D. 168th ENMC International Workshop: outcome measures and clinical trials in CharcotMarie-Tooth disease (CMT). Neuromuscul Disord. 2010;20(12): 839-846.

47. Komyathy K, Neal S, Feely S, et al. Anterior tibialis CMAP amplitude correlations with impairment in CMT1A. Muscle Nerve. 2013;47(4): 493-496.

48. Chung KW, Kim SB, Park KD, et al. Early onset severe and late-onset mild Charcot-Marie-Tooth disease with mitofusin 2 (MFN2) mutations. Brain. 2006;129(Pt 8):2103-2118.

49. Pareyson D, Reilly M, Rizzuto N, et al. Charcot-Marie-Tooth disease and ascorbic acid trials results of the CMT-TRIAAL and CMT-TRAUK In: Twentieth Meeting of the European Neurological Society 19-23 June 2010 Berlin, Germany. J Neurol. 2010;257:S104.

50. Feely SM, Laura M, Siskind CE, et al. MFN2 mutations cause severe phenotypes in most patients with CMT2A. Neurology. 2011;76(20): 1690-1696.

51. El-Abassi R, England JD, Carter GT. Charcot-Marie-Tooth Disease: an overview of genotypes, phenotypes, and clinical management strategies. PM R. 2014;6(4):342-355.

52. Burns J, Ramchandren S, Ryan MM, Shy M, Ouvrier RA. Determinants of reduced health-related quality of life in pediatric inherited neuropathies. Neurology. 2010;75(8):726-731.

53. Ramchandren S, Shy M, Feldman E, Carlos R, Siskind C. Defining disability: development and validation of a mobility-Disability Severity Index (mDSI) in Charcot-Marie-tooth disease. J Neurol Neurosurg Psychiatry. 2015;86(6):635-639. 
54. Johnson NE, Heatwole CR, Dilek N, et al. Quality-of-life in CharcotMarie-Tooth disease: the patient's perspective. Neuromuscul Disord. 2014;24(11):1018-1023.

55. Aboussouan LS, Lewis RA, Shy ME. Disorders of pulmonary function, sleep, and the upper airway in Charcot-Marie-Tooth disease. Lung. 2007;185(1):1-7.

56. Boentert M, Dziewas R, Heidbreder A, et al. Fatigue, reduced sleep quality and restless legs syndrome in Charcot-Marie-Tooth disease: a web-based survey. J Neurol. 2010;257(4):646-652.

57. Souza CC, Hirotsu C, Neves EL, et al. Sleep pattern in Charcot-MarieTooth disease type 2: report of family case series. J Clin Sleep Med. 2015;11(3):205-211.

58. de Carvalho Alcântara M, Nogueira-Barbosa MH, Fernandes RM, et al. Respiratory dysfunction in Charcot-Marie-Tooth disease type 1A. J Neurol. 2015;262(5):1164-1171.

59. Dematteis M, Pépin JL, Jeanmart M, Deschaux C, Labarre-Vila A, Lévy P. Charcot-Marie-Tooth disease and sleep apnoea syndrome: a family study. Lancet. 2001;357(9252):267-272.

60. Darquennes K, De Jonghe P, Daems D, De Backer W, Verbraecken J. Intermittent positive airway pressure by nasal mask as a treatment for respiratory insufficiency in a patient with Charcot-Marie-Tooth disease. Acta Clin Belg. 2006;61(4):176-181.

61. Benson B, Sulica L, Guss J, Blitzer A. Laryngeal neuropathy of CharcotMarie-Tooth disease: further observations and novel mutations associated with vocal fold paresis. Laryngoscope. 2010;120(2):291-296.

62. Boentert M, Knop K, Schuhmacher C, Gess B, Okegwo A, Young P. Sleep disorders in Charcot-Marie-Tooth disease type 1. J Neurol Neurosurg Psychiatry. 2014;85(3):319-325.

63. Rudnik-Schöneborn S, Röhrig D, Nicholson G, Zerres K. Pregnancy and delivery in Charcot-Marie-Tooth disease type 1. Neurology. 1993; 43(10):2011-2016.

64. Hoff JM, Gilhus NE, Daltveit AK. Pregnancies and deliveries in patients with Charcot-Marie-Tooth disease. Neurology. 2005;64(3):459-462.

65. Brock M, Guinn C, Jones M. Anesthetic management of an obstetric patient with Charcot-Marie-Tooth disease: a case study. AANA J. 2009; 77(5):335-337.

66. Chaudhry V, Chaudhry M, Crawford TO, Simmons-O'Brien E, Griffin JW. Toxic neuropathy in patients with pre-existing neuropathy. Neurology. 2003;60(2):337-340.

67. Holzbaur EL, Scherer SS. Microtubules, axonal transport, and neuropathy. $N$ Engl J Med. 2011;365(24):2330-2332.

68. Weimer LH, Podwall D. Medication-induced exacerbation of neuropathy in Charcot Marie Tooth disease. J Neurol Sci. 2006;242(1-2): $47-54$.

69. Attarian S, Vallat JM, Magy L, et al. An exploratory randomised double-blind and placebo-controlled phase 2 study of a combination of baclofen, naltrexone and sorbitol (PXT3003) in patients with CharcotMarie-Tooth disease type 1A. Orphanet J Rare Dis. 2014;9:199.

70. Chumakov I, Milet A, Cholet N, et al. Polytherapy with a combination of three repurposed drugs (PXT3003) down-regulates Pmp22 overexpression and improves myelination, axonal and functional parameters in models of CMT1A neuropathy. Orphanet J Rare Dis. 2014;9:201.

71. Mandel J, Bertrand V, Lehert P, et al. A meta-analysis of randomized double-blind clinical trials in CMT1A to assess the change from baseline in CMTNS and ONLS scales after one year of treatment. Orphanet $J$ Rare Dis. 2015;10:74.

72. Passage E, Norreel JC, Noack-Fraissignes $\mathrm{P}$, et al. Ascorbic acid treatment corrects the phenotype of a mouse model of Charcot-Marie-Tooth disease. Nat Med. 2004;10(4):396-401.

73. Burns J, Ouvrier RA, Yiu EM, et al. Ascorbic acid for CharcotMarie-Tooth disease type $1 \mathrm{~A}$ in children: a randomised, doubleblind, placebo-controlled, safety and efficacy trial. Lancet Neurol. 2009;8(6):537-544.

74. Micallef J, Attarian S, Dubourg O, et al. Effect of ascorbic acid in patients with Charcot-Marie-Tooth disease type 1A: a multicentre, randomised, double-blind, placebo-controlled trial. Lancet Neurol. 2009;8(12):1103-1110.
75. Verhamme C, de Haan RJ, Vermeulen M, Baas F, de Visser M, van Schaik IN. Oral high dose ascorbic acid treatment for one year in young CMT1A patients: a randomised, double-blind, placebo-controlled phase II trial. BMC Med. 2009; 7:70.

76. Pareyson D, Reilly MM, Schenone A, et al. Ascorbic acid in CharcotMarie-Tooth disease type 1A (CMT-TRIAAL and CMT-TRAUK): a double-blind randomised trial. Lancet Neurol. 2011;10(4):320-328.

77. Lewis RA, McDermott MP, Herrmann DN, et al. High-dosage ascorbic acid treatment in Charcot-Marie-Tooth disease type 1A: results of a randomized, double-masked, controlled trial. JAMA Neurol. 2013;70(8): 981-987.

78. Williams LL, O'Dougherty MM, Wright FS, Bobulski RJ, Horrocks LA. Dietary essential fatty acids, vitamin E, and Charcot-Marie-Tooth disease. Neurology. 1986;36(9):1200-1205.

79. Russell JW, Windebank AJ, Harper CM Jr. Treatment of stable chronic demyelinating polyneuropathy with 3,4-diaminopyridine. Mayo Clin Proc. 1995;70(6):532-539.

80. Sereda MW, Meyer zu Hörste G, Suter U, Uzma N, Nave KA. Therapeutic administration of progesterone antagonist in a model of Charcot-MarieTooth disease (CMT-1A). Nat Med. 2003;9(12):1533-1537.

81. Meyer zu Horste G, Prukop T, Liebetanz D, Mobius W, Nave KA, Sereda MW. Antiprogesterone therapy uncouples axonal loss from demyelination in a transgenic rat model of CMT1A neuropathy. Ann Neurol. 2007;61(1):61-72.

82. Sahenk Z, Nagaraja HN, McCracken BS, et al. NT-3 promotes nerve regeneration and sensory improvement in CMT1A mouse models and in patients. Neurology. 2005;65(5):681-689.

83. Sahenk Z, Galloway G, Clark KR, et al. AAV1.NT-3 gene therapy for charcot-marie-tooth neuropathy. Mol Ther. 2014;22(3):511-521.

84. Kuhlenbaumer G, Young P, Hunermund G, Ringelstein B, Stogbauer F. Clinical features and molecular genetics of hereditary peripheral neuropathies. J Neurol. 2002;249(12):1629-1650.

85. Vinci P. Gait rehabilitation in a patient affected with Charcot-MarieTooth disease associated with pyramidal and cerebellar features and blindness. Arch Phys Med Rehabil. 2003;84(5):762-765.

86. Sackley C, Disler PB, Turner-Stokes L, Wade DT, Brittle N, Hoppitt T. Rehabilitation interventions for foot drop in neuromuscular disease. Cochrane Database Syst Rev. 2009;(3):CD003908.

87. Sman AD, Raymond J, Refshauge KM, et al. Randomised controlled trial protocol of foot and ankle exercise for children with Charcot-Marie-Tooth disease. J Physiother. 2014;60(1):55; discussion 55 .

88. Lencioni T, Rabuffetti M, Piscosquito G, et al. Postural stabilization and balance assessment in Charcot-Marie-Tooth 1A subjects. Gait Posture. 2014;40(4):481-486.

89. Vinci P, Esposito C, Perelli SL, Antenor JA, Thomas FP. Overwork weakness in Charcot-Marie-Tooth disease. Arch Phys Med Rehabil. 2003;84(6):825-827.

90. Piscosquito G, Reilly MM, Schenone A, et al. Is overwork weakness relevant in Charcot-Marie-Tooth disease? J Neurol Neurosurg Psychiatry. 2014;85(12):1354-1358.

91. Rose KJ, Burns J, Wheeler DM, North KN. Interventions for increasing ankle range of motion in patients with neuromuscular disease. Cochrane Database Syst Rev. 2010;(2):CD006973.

92. Burns J, Bray P, Cross LA, North KN, Ryan MM, Ouvrier RA. Hand involvement in children with Charcot-Marie-Tooth disease type 1A. Neuromuscul Disord. 2008;18(12):970-973.

93. Dufek JS, Neumann ES, Hawkins MC, O'Toole B. Functional and dynamic response characteristics of a custom composite ankle foot orthosis for Charcot-Marie-Tooth patients. Gait Posture. 2014;39(1): 308-313.

94. Guillebastre B, Calmels P, Rougier PR. Assessment of appropriate ankle-foot orthoses models for patients with Charcot-Marie-Tooth disease. Am J Phys Med Rehabil. 2011;90(8):619-627.

95. Ramdharry GM, Day BL, Reilly MM, Marsden JF. Foot drop splints improve proximal as well as distal leg control during gait in CharcotMarie-Tooth disease. Muscle Nerve. 2012;46(4):512-519. 
96. Menotti F, Laudani L, Damiani A, Mignogna T, Macaluso A. An anterior ankle-foot orthosis improves walking economy in Charcot-MarieTooth type 1A patients. Prosthet Orthot Int. 2014;38(5):387-392.

97. Scheffers G, Hiller C, Refshauge K, Burns J. Prescription of foot and ankle orthoses for children with Charcot-Marie-Tooth disease: a review of the evidence. Phys Ther Rev. 2012;17(2):79-90.

98. Wegener C, Burns J, Penkala S. Effect of neutral-cushioned running shoes on plantar pressure loading and comfort in athletes with cavus feet: a crossover randomized controlled trial. Am J Sports Med. 2008; 36(11):2139-2146.

99. Vinci P, Gargiulo P. Poor compliance with ankle-foot-orthoses in Charcot-Marie-Tooth disease. Eur J Phys Rehabil Med. 2008; 44(1):27-31.

100. Phillips MF, Robertson Z, Killen B, White B. A pilot study of a crossover trial with randomized use of ankle-foot orthoses for people with Charcot-Marie-tooth disease. Clin Rehabil. 2012;26(6):534-544.

101. Faldini C, Traina F, Nanni M, et al. Surgical treatment of cavus foot in Charcot-Marie-tooth disease: a review of twenty-four cases: AAOS exhibit selection. J Bone Joint Surg Am. 2015;97(6):e30.
102. Boffeli TJ, Tabatt JA. Minimally Invasive Early Operative Treatment of Progressive Foot and Ankle Deformity Associated With CharcotMarie-Tooth Disease. J Foot Ankle Surg. 2015;54(4):701-708.

103. Burns J, Raymond J, Ouvrier R. Feasibility of foot and ankle strength training in childhood Charcot-Marie-Tooth disease. Neuromuscul Disord. 2009;19(12):818-821.

104. El Mhandi L, Millet GY, Calmels P, et al. Benefits of interval-training on fatigue and functional capacities in Charcot-Marie-Tooth disease. Muscl Nerve. 2008;37(5):601-610.

105. Chetlin RD, Gutmann L, Tarnopolsky M, Ullrich IH, Yeater RA. Resistance training effectiveness in patients with Charcot-Marie-Tooth disease: recommendations for exercise prescription. Arch Phys Med Rehabil. 2004;85(8):1217-1223.

106. Saporta ASD, Sottile SL, Miller LJ, Feely SME, Siskind CE, Shy ME. Charcot-Marie-Tooth disease subtypes and genetic testing strategies. Ann Neurol. 2011;69(1):22-33.

107. Miller LJ, Saporta ASD, Sottile SL, Siskind CE, Feely SME, Shy ME. Strategy for genetic testing in Charcot-Marie-disease. Acta Myol. 2011;30(2):109-116
Journal of Multidisciplinary Healthcare

\section{Publish your work in this journal}

The Journal of Multidisciplinary Healthcare is an international, peerreviewed open-access journal that aims to represent and publish research in healthcare areas delivered by practitioners of different disciplines. This includes studies and reviews conducted by multidisciplinary teams as well as research which evaluates the results or conduct of such teams or

\section{Dovepress}

healthcare processes in general. The journal covers a wide range of areas and welcomes submissions from practitioners at all levels, from all over the world. The manuscript management system is completely online and includes a very quick and fair peer-review system. Visit http://www.dovepress.com/testimonials.php to read real quotes from published authors.

Submit your manuscript here: http://www.dovepress.com/journal-of-multidisciplinary-healthcare-journal 